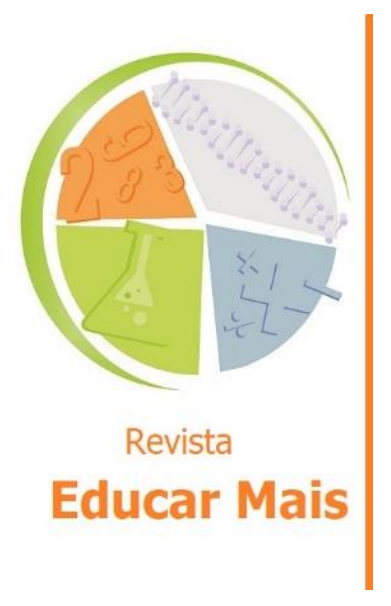

\title{
A formação do tradutor e intérprete educacional em Minas Gerais: análises e reflexões de intérpretes formadores
}

\author{
The formation of the translator and interpreter educational in Minas \\ Gerais: analysis and reflections of interpreters formers
}

La formacion del traductor e intérprete educacional en Minas Gerais: análisis y reflexión de los intérpretes formadores

Thiago Lemes de Oliveira ${ }^{1}$ (D)

\section{RESUMO}

A função do tradutor intérprete de Libras foi reconhecida como profissão no Brasil pela Lei Federal 12.319 de 2010. Esta lei que, por consequência, reconhece a função do intérprete educacional, não dá providências específicas quanto a instituição de cursos de formação em nível superior ou técnico destes profissionais. Esta pesquisa tem por objetivo, analisar e refletir os impactos deste problema na sua identidade profissional e consequentemente de sua atuação na área educacional a partir da ótica, reflexão e análise dos Intérpretes de Língua de Sinais Formadores (ILSF). A análise de dados desta pesquisa foi realizada a partir do estudo das legislações específicas quanto a formação profissional, das produções científicas sobre as atribuições e identidade do Tradutor e Intérprete de Língua de Sinais Educacional (TILSE) e dos Intérpretes de Língua de Sinais Formadores (ILSF), e dos depoimentos dos formadores de TILSEs do estado de Minas Gerais. Os resultados dessa pesquisa apresentam, portanto, um problema relacionado a formação e as atribuições funcionais desses profissionais aos seus pares, à sociedade civil, ao poder público e às instituições de ensino superior.

Palavras-chave: Intérprete educacional; Libras; Tradutor e intérprete; Intérprete formador.

\begin{abstract}
The role of translator and interpreter of Libras was recognized as a profession in Brazil by Federal Law 12.319 of 2010. This law that consequently recognizes the role of the educational interpreter does not guarantee the specific institution of training courses at a higher or technical level of these professionals. Thus, this research aims to analyze and reflect the impacts of this problem on their professional identity and consequently in the educational área from the perspective, reflection and analysis of Interpreters of language sign formers (ILSF) The data analysis of this research was carried out based on the study of the specific legislation regarding professional training, scientific productions about the attributions of the translator and interpreter of language signs educational (TILSE) and interpreter of language sign former (ILSF), and the testimonies of formers of TILSES from the state of Minas Gerais. The results of this research therefore presents a problem related to the formation and functional attribuctions of these professionals for their pairs, to civil society, public authorities and higher educational institutions.
\end{abstract}

Keywords: Educational interpreter; Libras; Translator and interpreter; Interpreter former.

\section{RESUMEN}

La función del traductor e intérprete de Libras fue reconocida como profesión en Brasil por la Ley Federal 12.319 de 2010. Esta ley que, luego, reconoce la función del intérprete educacional, no hace predicciones especificas acerca de la implantación de cursos de formación a nivel superior o técnico de esos profesionales. La

${ }^{1}$ Doutorando em Estudos Linguísticos pela Universidade Federal de Uberlândia (UFU), Uberlândia/MG - Brasil. E-mail: thilemesoli@gmail.com 
investigación tiene como objetivo analizar y reflexionar sobre los impactos de este problema en la identidad profesional y consecuentemente, en su actuación en el área educacional, a través de la mirada, de la reflexión y del análisis de los Intérpretes de Língua de Sinais Formadores (ILSF). El análisis de datos de esta investigación fue realizado tras el estudio de las legislaciones especificas acerca de la formación profesional, de las producciones científicas sobre las atribuciones e identidad del traductor e intérprete de Língua de Sinais Educacional (TILSE) y de los intérpretes de Língua de Sinais Formadores (ILSF), y de los relatos de profesionales formadores de TILSEs del estado de Minas Gerais. Los resultados de esa investigación presentan, por lo tanto, un problema relacionado a la formación y a las atribuciones funcionales de esos profesionales a sus iguales, a la sociedad civil, al poder público y a las instituciones de enseñanza superior.

Palabras clave: Intérprete educacional; Libras; Traductor e intérprete; Intérprete formador.

\section{INTRODUÇÃO: QUEM É O INTÉRPRETE FORMADOR?}

O trabalho a seguir é fruto de investigações cientificas desenvolvidas durante o curso de Mestrado Profissional em Educação na Universidade Federal de Lavras (UFLA) enquanto membro participante do projeto de pesquisa IDOLINi. Tem sua aprovação devidamente registrada pelo Comitê de Ética e Pesquisa (CEP) vinculada à UFLA sob o parecer de número 2.866.568 em 20 de agosto de 2018ii. Emerge das inquietações de um professor formador de tradutores e intérpretes de Língua Brasileira de Sinais (Libras) para a educação, sobre como seu deu a formação de outros professores formadores atuantes e de como se dá a formação desses profissionais no cenário atual da educação.

Para explanar as questões desta pesquisa, bem como sustentá-la teoricamente, faz-se necessário compreender o sujeito da pesquisa, a saber, o formador de tradutores e intérpretes de Libras educacionais. O surgimento desse profissional deve-se, em grande parte, à grande e crescente demanda de conferir acessibilidade comunicacional aos sujeitos Surdos ${ }^{\mathrm{iii}}$, cada vez mais presentes e atuantes na sociedade, implicando na necessidade de novos tradutores e intérpretes de Libras para atuar em diferentes contextos da vida social, principalmente no contexto escolar. Assim, será apresentado aqui as diferentes funções e nomenclaturas designadas a estes profissionais, que em si, justificam a função do Intérprete Formador.

O tradutor e intérprete de Librasiv é o principal canal de comunicação e mediação entre surdos e ouvintes não fluentes em Libras, é, portanto, um mediador cultural (MOURA e CAVALCANTE, 2013). Entre as diferentes áreas de atuação de um tradutor e intérprete de Libras está a escola, que ao demandar a necessidade destes profissionais para acompanhar seus alunos surdos, contribuiu diretamente para o surgimento de um novo perfil profissional - o Intérprete Educacional (IE). Em anos mais recentes, esse mesmo profissional foi designado com diferentes nomenclaturas pelos pesquisadores da área. A nomenclatura proposta de forma mais recente por Martins (2016): Tradutor e Intérprete de Língua de Sinais Educacional - TILSE, foi a nomenclatura escolhida para se referir a esse profissional neste trabalho. Este profissional em diferentes contextos, e principalmente no contexto escolar, torna-se voz e ouvidos do aluno Surdo. As diferentes funções de um TILSE podem ainda influenciar a identidade profissional desses sujeitos, segundo Martins (2016) isso ocorre por tratar-se de das seguintes funções distintas:

Nota-se, no entanto, que no espaço escolar há a atuação nas duas modalidades: interpretação e tradução. $O$ cotidiano da sala de aula é permeado mais pela ação interpretativa, pois há a instantaneidade presente nas falas dos sujeitos a qual pede a transposição de discursos de uma língua para outra. Todavia, em avaliações o TILSE poderá atuar como tradutor, bem como em produções de materiais didáticos, e em tantos outros momentos que podem ser necessários e que solicitam produtos 
finais versados de uma língua para outra, com tempo apropriado para a sua produção. (2016, p.151)

Com isso, o trabalho de um TILSE vai muito além da função de traduzir as falas presentes no dia a dia do aluno, impactando também na sua relação com o meio, nas relações interpessoais, e até mesmo na relação intrapessoal, tendo em vista que ele passa a ser um modelo social para os alunos surdos que acompanha ao longo de sua carreira, representando assim "uma figura significativa na constituição do sujeito surdo". (MOURA e CAVALCANTE, 2013, p.85). Já Lacerda (2009) usou a nomenclatura Intérprete educacional (IE) para designar a identidade do tradutor e intérprete de Libras que atua no espaço escolar, para ela, essa identidade é influenciada também por uma série de funções distintas atribuídas e esse profissional, além da de simplesmente traduzir e interpretar. Segundo ela:

[...] o trabalho do IE vai além de fazer escolhas ativas sobre o que deve traduzir, envolvendo também modos de tornar conteúdos acessíveis para o aluno, ainda que implique solicitar ao professor que reformule sua aula, pois uma tradução correta do ponto de vista linguístico nem sempre é a melhor opção educacional para propiciar o conhecimento, principalmente quando os alunos são crianças ainda em fase de aquisição da Libras. (2009, p. 35)

Por fim, surgem os Intérpretes de Língua de Sinais Formadores (ILSF) e antes de dissertar sobre a atuação destes profissionais, e relatar como se deu o seu surgimento, convém justificar a nomenclatura utilizada aqui. O motivo pelo uso de ILSF para Intérpretes de Língua de Sinais Formadores objetiva-se a distinguir o campo específico de atuação, na educação, existente no estado de Minas Gerais, onde tais profissionais exercem a função de professores, além da função de tradutores e intérpretes, esse papel em si, os diferencia dos demais tradutores e intérpretes de Libras mencionados anteriormente.

Os ILSF, sujeitos dessa pesquisa, conforme apresentado anteriormente, atuam ou já atuaram no estado de Minas Gerais vinculados aos Centros de Capacitação de Profissionais da Educação e Atendimento às Pessoas com Surdez (CAS). Ao relatar que tais profissionais exercem a função de professores, entende-se que essa identificação, em primeira instância, ocorre no ato de sua designação funcional conforme a Resolução $2903^{\vee}$ de 24 de fevereiro de 2016, que em seu anexo 1 sobre a composição da equipe de trabalho dos CAS estabelece a contratação de "professor/regente intérprete de Libras", sendo este profissional, após contratado, designado pela Secretaria de Estado de Educação de Minas Gerais como professor de educação básica (PEB).

Em segunda instância ocorre uma autodenominação dos professores intérpretes como ILSF, e que devido ao seu uso constante, foi convencionado pelos demais profissionais e agentes do CAS e das Secretarias Regionais de Educação do estado de Minas Gerais. Essa autodenominação, consiste em uma ação coletiva, dos ILSFs, intencionada a distinguir seu papel, bem como sua identidade profissional, uma vez que os documentos legais que os designam, não o fazem. Sobre isso a cartilha CAS - Histórico e diretrizes de funcionamento (2017) estabelece:

O candidato ao cargo de Tradutor e Intérprete de Libras para trabalhar no CAS e que for classificado como apto em seu processo avaliativo automaticamente será considerado apto para atuar como Intérprete Educacional na Rede Estadual de Ensino (p.11).

Apesar da cartilha CAS - Histórico e diretrizes de funcionamento não distinguir de forma clara a função ou identidade profissional do ILSF, nota-se essa distinção no uso das nomenclaturas Tradutor 
e Intérprete de Libras e Intérprete Educacional. Cabe aqui ressaltar que, no estado de Minas Gerais, todo ILSF um dia já foi um TILSE e que para tornar-se ILSF precisa atender a algumas exigências estabelecidas pelas resoluções 2903/2016 e 3995/2018, como: possuir licenciatura plena em qualquer área, especialização ou cursos de capacitação em Libras e avaliação de aptidão do CAS para ILSF, realizada mediante banca de proficiência do próprio CAS, geralmente composta por outros ILSFs e professores Surdos, requisitos esses que não são exigidos para a atuação e designação dos TILSEs, sendo tais requisitos aplicados à eles, apenas como critério de classificação e/ou desempate no ato da contratação.

Além disso, faz-se necessário mencionar que todo esse processo formativo, que será detalhado mais a frente, é recente, pois, a profissão do tradutor e intérprete de Libras só foi reconhecida como profissão no Brasil no ano de 2010 pela Lei Federal 12.319, e que devido a algumas brechas, já tramita nas esferas governamentais competentes, o Projeto de Lei 9.382/2017 que a revoga e dispõe sobre o exercício profissional e condições de trabalho do profissional tradutor, guia-intérprete e intérprete de Libras.

Quanto a atuação do ILSF, destacam-se as atribuições funcionais que o caracteriza como docente e o distingue do TILSE. Assim a cartilha CAS - Histórico e diretrizes de funcionamento (2017) entre seus objetivos, atribui:

- Oferecer o Curso de Libras para professores e demais profissionais da educação;

- Apoiar estudantes e familiares na aprendizagem da Libras;

- Promover a formação continuada dos profissionais da educação para a oferta da educação bilíngue;

- Capacitar professores do AEE - sala de recursos, para o atendimento adequado ao estudante surdo;

- Avaliar as competências tradutórias e de interpretação de pessoas interessadas em atuar no contexto educacional como Tradutor e Intérprete de Libras;

- Capacitar Tradutores e Intérpretes de Libras para atuarem nas escolas;

- Promover capacitação de professores surdos para o ensino da Libras;

- Produzir materiais didáticos acessíveis ao estudante surdo (vídeos didáticos em língua de sinais e legendados, dicionários de português/língua de sinais, textos adaptados, mapas, jogos pedagógicos adaptados e outros);

- Dar suporte pedagógico aos Instrutores de Libras lotados nas SREs, responsáveis pelo Curso de Libras e apoio aos estudantes surdos no AEE;

- Dar suporte pedagógico às SREs e escolas nos assuntos referentes à área da surdez (p.6).

Com isso, desde a oficialização e reconhecimento da profissão do tradutor e intérprete de Libras e consequentemente do TILSE, algumas pesquisas discorrem sobre sua formação e função. Nascimento, Bezerra, Albres e Santiago (2012) analisam propostas de cursos de extensão como possíveis soluções para formação desse profissional. Almeida e Lodi (2014) defendem a parceria entre tradutores e intérpretes e professores surdos, e a participação ativa na comunidade surda, como 
ferramenta fundamental do processo formativo. Ferreira (2015) investiga o processo de formação de tradutores e intérpretes em cursos de Letras-Libras nas modalidades de licenciatura e bacharelado. Martins (2016) reafirma a ação pedagógica dos TILSEs e apresenta os desafios de formação desses sujeitos. Gumieiro e Pereira (2018) refletem sobre a constituição profissional do tradutor e intérprete de Libras segundo legislações vigentes e suas especificidades. Albres e Rodrigues (2018) discorrem sobre as funções do intérprete educacional em relação às políticas públicas educacionais. Esta pesquisa, no entanto, distingue-se de todas as outras, por investigar a formação e a função do ILSF, bem como conferir espaço para suas reflexões quanto a sua formação e a do TILSE no cenário mineiro. Em tempo, assemelha-se às pesquisas resenhadas por averiguar e discutir os processos formativos de um profissional vital, na realidade inclusiva de Minas Gerais, para a educação dos sujeitos Surdos.

Nessa direção, surge um problema que será discutido neste trabalho a partir das seguintes perguntas de pesquisa: (1) Qual seria a melhor formação, inicial e continuada, para os ILSFs e TILSEs sob a ótica dos ILSFs do estado de Minas Gerais? (2) Existem falhas neste processo, e em caso positivo, como abordá-las? (3) Como se dá a formação do ILSF e do TILSE, na atualidade, para atender alunos surdos nos diversos níveis escolares?

Com esse ponto de partida, as respostas a esses questionamentos, encontradas através dos processos investigativos aplicados durante essa pesquisa, possibilitaram explorar o que pensam os ILSF de Minas Gerais, identificando suas necessidades e anseios. Além disso, possibilitarão futuras investigações da pesquisa iniciada por Lacerda quanto a identidade do $\mathrm{IE}$, ao refletir sobre sua formação profissional e função social diante da perspectiva dos próprios sujeitos. Deste modo, 0 presente trabalho foi organizado da seguinte forma: o tópico "Metodologia" caracteriza essa pesquisa a partir de sua posição epistemológica, seu método e técnicas de coletas dos dados que compõem seu corpus. O tópico "Formação em foco" discute a formação dos tradutores e intérpretes de Libras na atualidade, tendo por foco os ILSF, a partir das teorias de identidade profissional, agência. Reflete ainda quanto a sua função e relevância social, pela ótica de pesquisadores da área e das políticas públicas em vigência. O terceiro tópico "Deles por eles" apresenta uma análise da formação do ILSF partindo de seus depoimentos e reflexões, e o que pensam sobre a formação dos TILSEs na atualidade. Por fim, em "Considerações finais" são ponderadas as proposituras, idealizadas pelos participantes durante a investigação deste trabalho, de como formar TILSEs e novos ILSFs melhor preparados para contemplar a necessidade do atendimento de alunos surdos em todos os níveis escolares.

\section{METODOLOGIA}

Os sujeitos de estudo deste projeto são os ILSFs do estado de Minas Gerais, mais especificamente sua formação, identidade profissional e reflexões. Trata-se então de uma pesquisa qualitativa etnográfica em primeira instância, que permite ao pesquisador um contato direto com a situação ou pessoas pesquisadas (ANDRÉ, 2008). Sobre isso, vale ressaltar que a pesquisa foi desenvolvida ao longo de dezoito meses sendo o pesquisador também um participante.

Em segunda instância, caracteriza-se também uma pesquisa bibliográfica, uma vez que foi necessária a pesquisa de publicações acadêmicas e cientificas, no intuito de classificar o papel do profissional, suas atribuições e relevância social. Sobre a questão metodológica, Gil discorre que a pesquisa bibliográfica: 
[...] é elaborada com base em material já publicado. Tradicionalmente, inclui material impresso, como livros, revistas, jornais, teses, dissertações, e anais de eventos científicos. Todavia, em virtude de disseminação de novos formatos de informação, estas pesquisas passaram a incluir outros tipos de fontes, como discos, fitas magnéticas, CDs, bem como o material disponibilizado pela Internet. (GIL, 2016 p.29)

Ainda em relação à pesquisa bibliográfica foi necessário efetuar uma análise em documentos legais como: resoluções, projeto de lei, leis, decretos e convenções constitucionais, a fim de averiguar as políticas públicas que regem as atividades destes profissionais na atualidade.

\subsection{Método e coleta dos dados}

Concomitante à pesquisa documental, a fim de se conhecer a formação e a construção identitária dos ILSF, foi realizada uma pesquisa de campo em ambiente virtual e presencial. No âmbito presencial foram realizados encontros e reuniões com o fim de discutir a formação, a prática e as reflexões pertinentes a profissão de cada participante da pesquisa, tendo sido tais atividades aprovadas pelo comitê de ética para o qual o projeto de pesquisa foi submetido. Como procedimento de coleta, cada reunião foi registrada em forma de ata e compartilhada posteriormente com o grupo em suas redes sociais. No âmbito virtual os participantes foram convidados a responder um questionário semiestruturados, permitindo a coleta de depoimentos a partir de suas respostas, mediante a assinatura de um Termo de Consentimento Livre e Esclarecido (TCLE). Esta segunda fase também permitiu ao pesquisador coletar dados quantitativos relacionados à formação e atuação social, acadêmica e profissional dos participantes. No questionário, os participantes responderam às perguntas: Quando e como se deu o seu primeiro contato com a Libras? Há quanto tempo atua como TILSE e ILSF? Qual é a sua formação para atuar como ILSF? Quando avalia a sua própria formação como TILSE e posteriormente como ILSF, existe alguma insatisfação ou necessidade que julgue relevante para seu desenvolvimento profissional? Para você, qual seria a formação inicial e continuada ideal para formar um ILSF e TILSE? Como você vis/umbra a formação desses profissionais em uma perspectiva futura?

\subsection{Colaboradores}

Durante a realização dessa pesquisa e coleta dos dados, encontravam-se no estado de Minas Gerais quatorze ILSFs em exercício. Todos os quatorze ILSFs foram convidados para participar da pesquisa, entretanto, aceitaram e participaram sete profissionais, incluindo o autor, sendo este grupo os colaboradores desse trabalho. Vale ressaltar que os participantes encontravam-se atuando em cinco regiões do estado: norte, sul e sudoeste, central mineira, Triângulo Mineiro/Alto Parnaíba e Jequitinhonha. A investigação desses participantes intencionou compreender como se deu sua formação inicial, em como ocorre sua formação continuada, e quais são suas necessidades e anseios durante a constituição de sua identidade profissional.

No próximo tópico serão apresentados o perfil dos participantes, bem como particularidades referentes a sua atuação profissional, e da sua inserção na comunidade surda e aquisição da Libras. Para conferir sigilo aos participantes, cada um deles foi representado por iniciais fictícias que não correspondem ao seu nome real. 


\subsection{Perfil dos colaboradores}

Tabela 1: dados quantitativos da pesquisa.

\begin{tabular}{|c|c|c|c|c|c|}
\hline & Gênero & Idade & $\begin{array}{c}\text { Idade que teve o } \\
\text { primeiro contato } \\
\text { com a Libras }\end{array}$ & $\begin{array}{c}\text { Tempo de } \\
\text { atuação } \\
\text { como TILSE }\end{array}$ & $\begin{array}{c}\text { Tempo de } \\
\text { atuação como } \\
\text { ILSF }\end{array}$ \\
\hline Participantes & Feminino & 31 anos & 17 anos & 14 anos & 3 anos \\
\hline NML & Feminino & 32 anos & 17 anos & 14 anos & 4 anos \\
\hline KC & Feminino & 32 anos & 0 anos & 14 anos & 5 anos \\
\hline BLO & Masculino & 33 anos & 14 anos & 15 anos & 4 anos \\
\hline AFP & Masculino & 33 anos & 18 anos & 12 anos & 3 anos \\
\hline PPM & Masculino & 34 anos & 18 anos & 15 anos & 5 anos \\
\hline APV & Feminino & 35 anos & 18 anos & 15 anos & 5 anos \\
\hline Média total: & - & 32,7 anos & 17 anos & 13 anos & 4 anos \\
\hline
\end{tabular}

Os dados quantitativos dessa pesquisa descritos na tabela 1 revelaram que dos sete participantes, quatro mulheres e três homens, a média de idade dos profissionais é de 32 anos e 7 meses, sendo que a idade média em que tiveram o primeiro contato com a comunidade surda e com a Libras foi aos 17 anos. Foi possível mensurar ainda que todos os participantes possuem em média 13 anos de atuação como TILSEs e aproximadamente 4 anos como ILSFs.

Após a coleta dos dados e das análises documentais, com base na abordagem qualitativa interpretativista, o pesquisador-participante, amparado pelas contribuições de seus colegas de profissão, compartilha algumas reflexões sobre as questões norteadoras dessa pesquisa, seus possíveis desdobramentos e soluções no intuito de estimular o leitor a não somente conhecer, como também explorar este assunto. Quanto a reflexibilidade do pesquisador sobre a pesquisa, deve ser compreendida como parte da produção do conhecimento. Conforme Flick:

[...] os métodos qualitativos consideram a comunicação do pesquisador em campo, como parte explicita da produção do conhecimento, em vez de simplesmente encarála como uma variável a interferir no processo. A subjetividade do pesquisador, bem como daqueles que estão sendo estudados, tornam-se parte do processo de pesquisa. As reflexões dos pesquisadores sobre as suas próprias atitudes e observações em campo, suas impressões, irritações, sentimentos etc., tornam-se dados em si mesmos, constituindo parte da interpretação e são, portanto, documentadas [...] (FLICK, 2009 p.25)

Para que a discussão destes resultados fosse possível, além da subjetividade do pesquisador, que será detalhada e discutida mais a frente, foi necessário ainda, uma apropriação das teorias de identidade lançando um olhar para a formação desses profissionais e todo seu processo de agência, que serão apresentadas no próximo tópico. 


\section{FORMAÇÃO EM FOCO}

A fim de compreender a constituição da identidade profissional dos profissionais sujeitos dessa pesquisa, esta seção foi organizada em três subseções que versarão sobre a formação social, formação autônoma e formação curricular acadêmica.

\section{A) Da formação social}

Cada um dos sete participantes desta pesquisa, seis tiveram seu primeiro contato com a comunidade surda e consequentemente com a Libras durante sua adolescência, e uma durante seus primeiros anos de vida. Dos sete participantes, seis tiveram esse contato em espaços religiosos, impulsionados pelo desejo de compartilhar suas crenças com a população surda através da educação bíblica. Outra participante, teve a Libras como primeira língua e o contato com a comunidade surda no seio familiar, uma vez que é filha ouvinte de pais Surdos; entretanto, segundo ela, "[...] foi só na adolescência que me dei conta que aqueles gestos eram uma língua e que eu poderia trabalhar com ela" (MPS, Intérprete formadora, 2018).

O fato do primeiro contato desses profissionais com a Libras não ter ocorrido em uma esfera acadêmica ou corporativa, com um objetivo profissional, corrobora com trabalhos recentes de pesquisadores brasileiros, ao atestar que a formação do tradutor e intérprete de Libras tem sua origem em contextos informais e/ou religiosos (ASSIS, 2012, 2013, 2014; MARTINS e NASCIMENTO, 2015). Tais contextos, embora contribuam significativamente para a formação da identidade profissional, não possuem esse objetivo, portanto, não conferem conhecimentos técnico-específicos necessários à prática desses sujeitos. Nesse viés, cada sujeito, a partir de suas necessidades e interesses pessoais, envereda por uma jornada distinta rumo a formação profissional. No que tange aos ILSFs, que exercem acima de tudo uma função docente, essa jornada pode ser compreendida pelas teorias de agência e identidade docente.

Pode-se se dizer que o ILSF ao ser designado como professor regente no estado de Minas Gerais e ter entre suas muitas atribuições o ensino de Libras, constitui-se também um professor de línguas, que em anos recentes, no âmbito da Línguistica Aplicada, tem ganhado mais espaço, em pesquisas que visam compreender como se constitui sua identidade. No cenário internacional essas pesquisas são realizadas por pesquisadores como Nóvoa (2000) e Barkhuizen (2017) por exemplo, enquanto no cenário nacional tais contribuições podem ser encontradas nas pesquisas de Abrahão (2014), Barcelos (2015, 2016), Souza (2016), Reichmann e Romero (2019). Tais pesquisadores concordam que a identidade docente do professor de línguas, é característica por ser uma identidade dinâmica, marcada pelas estruturas sociais onde está inserido, múltipla, pelas culturas em que o indivíduo transita e consequentemente se apropria, e autônoma, pelas escolhas formativas que são feitas pelo sujeito quanto ao profissional que deseja ser. Nesse último ecoa o conceito de agência, que será discutida na próxima seção.

\section{B) Da formação por agência}

Para Huang (2013) agência está diretamente relacionada com as escolhas pessoais de cada indivíduo, ele explica ainda que tais escolhas não são aleatórias ou desconexas, mas que são reflexos das necessidades encontradas por esse indivíduo, nas estruturas sociais em que está inserido e nas suas transformações. 
Para Benson (2017) agência vai além da simples capacidade de escolha, para ele, ela descreve as ações que frequentemente tendem a escapar do condicionamento social e das restrições que este impõe. Nessa perspectiva, emerge da agência a autonomia, que quando evidenciada por um professor, não se trata apenas de exercer controle sobre suas ações. Segundo Benson "a autonomia não é tanto controlar as ações individuais do hoje ou do amanhã (penso que talvez seja uma parte disso), mas direcionar as ações atuais para objetivos de longo prazo". (2017, p.19. Tradução minha. $)^{\text {vi }}$

Desta forma, como vimos nas teorias resenhadas, é possível responder a primeira pergunta desta pesquisa, compreendendo que a formação tanto dos ILSFs quanto dos TILSEs no cenário nacional atual, ainda ocorre de forma autônoma, independente e multifacetada, projetando seus objetivos às metas de longo prazo, como descrito por Benson. Esse tipo de agenciamento, por exemplo, é claramente percebido nas palavras de APV vii ao dizer:

Comecei a aprender Libras na igreja, para ensinar a Bíblia aos Surdos. Quando vi que meu trabalho voluntário poderia ser minha fonte de renda e profissão, comecei a fazer todos os cursos de Libras que apareciam, assisti palestras, interpretei em muitos eventos diferentes, até que decidi entrar na faculdade. (APV, Intérprete formadora, 2017)

As palavras de APV assemelham-se muito a dos outros seis participantes, que como ela, iniciaram sua jornada profissional no trabalho informal e/ou voluntário, para depois, pela necessidade individual e coletiva, aperfeiçoar seus conhecimentos e prática, priorizando o profissionalismo.

\section{C) Da formação curricular acadêmica}

No ano de 2006, teve início no Brasil o primeiro curso superior de Letras-Libras nas modalidades de bacharelado e licenciatura, ofertados pela Universidade Federal de Santa Catarina e posteriormente por instituições parceiras. Num primeiro momento o programa selecionou 500 estudantes, sendo que 447 são surdos e 53 são ouvintes bilíngues residentes em nove estados brasileiros (QUADROS e STUMPF, 2009). Desde então, outras instituições de ensino superior do país, privadas e públicas, passaram a ofertar esses cursos, que visam formar na licenciatura professores para o ensino de Libras como primeira língua e Língua Portuguesa como segunda língua, e no bacharelado tradutores e intérpretes de Libras. Diante desse breve histórico, ressalta-se que os ILSFs aqui pesquisados, não se formaram nesses cursos, e tampouco tecem suas reflexões críticas sobre esses cursos já existentes, ou pelos profissionais graduados em tais cursos e modalidades.

Os ILSFs participantes envolvidos nesse trabalho vêm de diferentes lugares, e possuem uma formação híbrida e mesclada, o que os permitem idealizar uma formação mais voltada para suas necessidades específicas, e atribuições inerentes a sua prática, como se apresenta a seguir.

Dos sete participantes, seis escolheram a licenciatura em Pedagogia, e um a licenciatura em Letras, como forma de aprimorar seus conhecimentos e formação. Todos os participantes são especialistas em Libras, e continuamente participam de eventos e cursos de extensão para atualização profissional. Entretanto, tais formações parecem insuficientes para atender às necessidades especificas dos ILSFs e dos TILSEs, já que a insuficiência está diretamente atrelada tanto a complexidade de suas atribuições laborais, quanto a falta de normativas legislativas que especifiquem e orientem sua formação. Sobre essas complexas atribuições laborais, me apoio em Santos que destaca:

Quanto a atuação profissional, a realidade é que o intérprete educacional está sempre no limite das relações: entre duas línguas de modalidades completamente distintas, 
entre o professor e o aluno, entre o que é dito e o que é compreendido, entre o ensino do conceito e os sentidos apreendidos, entre uma atuação neutra/imparcial e o envolvimento com a informação/significação. (2014, p. 86)

Ainda quanto a atuação dos TILSEs, Santos e Lacerda ressaltam:

Com relação ao trabalho em sala de aula, ressalta-se que este envolve linguagem, escolhas por parte do IE, reflexão, relações sociais com diferentes sujeitos, e participação no processo de ensino e aprendizagem. (2015 p. 512)

Sobre a atuação do ILSF, um participante comentou:

É minha responsabilidade preparar e desenvolver cursos, avaliar e reavaliar os intérpretes que estão nas escolas, encontrar novos profissionais em potencial, mapear os intérpretes da região e suas dúvidas, sanar suas dúvidas, dar palestras para professores sobre a relação deles com o intérprete, e daí começar tudo de novo. (AFP, Intérprete formador, 2018)

Quanto a falta de especificações na legislação vigente, me balizo na lei 12.319 de 2010, a mais recente, que ao reconhecer a profissão do tradutor e intérprete de Libras não dá providências quanto a formação do TILSE ou do ILSF direcionando-a de forma detalhada. Nela a formação profissional do tradutor e intérprete de Libras, deve se dar a partir de cursos de educação profissional, de extensão universitária, cursos de formação continuada promovidos por instituições de ensino superior ou ainda por organizações da sociedade civil representativas da comunidade surda.

As falhas encontradas nessa política pública, corroboram significativamente para uma lacuna a ser preenchida por aspectos de uma formação híbrida e pelas experiências tanto do TILSE, quanto dos ILSF. Além disso, a ausência de direcionamentos, potencializa, nesses profissionais, insatisfações, necessidades e reflexões críticas, quanto sua formação e prática. Com isso, retomando às primeiras duas perguntas dessa pesquisa, quanto a como se dá a formação do ILSF e do TILSE, na atualidade, e das falhas existentes nesse processo o próximo tópico objetiva compartilhar e discutir alguns anseios e reflexões críticas dos participantes quanto a sua própria formação e à formação que conferem aos TILSEs.

\section{DELES POR ELES}

Retomando o caráter descritivo desta pesquisa qualitativa e o fato de ser o pesquisador também participante, como apresentado na metodologia proposta, considera-se a subjetividade do pesquisador, ou seja suas percepções, impressões, sentimentos, irritações e reflexões, como dados e ferramentas para sua interpretação (FLICK, 2009). Por isso, alguns momentos dessa discussão poderão ser expressos em primeira pessoa.

Posto isso, faz-se relevante mencionar que o teor das reuniões realizadas para pensar e discutir tanto a prática quanto a formação dos ILSFs, era sempre permeada por sentimentos de ansiedade, insatisfação, insegurança e muitas vezes raiva.

Por exemplo, ao questionar sobre as atribuições da profissão, sendo destacada a função de conferir formação continuada e preparo aos TILSEs, um dos participantes exclamou:

Tenho que preparar os intérpretes para o trabalho em sala de aula, mas quem me prepara para prepará-los? Não existem cursos específicos, muito menos incentivo para que possamos fazê-los! (BLO, Intérprete formador, 2018). 
Nesse momento, senti uma comoção coletiva, e uma partilha do sentimento expresso por aquele participante. O comentário expresso por esse participante, concedeu ao pesquisador, aparato para outro questionamento: o que pensavam aqueles participantes sobre a atual formação de Intérpretes formadores e TILSEs no cenário nacional? O que sabiam sobre isso? Tal questionamento foi proposto num segundo momento, em um questionário semiestruturado mediante a aplicação de formulário virtual, como mencionado anteriormente. Quando respondido pelos participantes, foi uma surpresa para este pesquisador, perceber que eles não atribuíam falhas apenas ao sistema educacional ou político nacional, mas a eles mesmos e aos profissionais por eles formados, como se pode observar nas respostas abaixo:

Acredito que a grande maioria dos intérpretes não têm formação adequada e não são exigidos critérios mínimos devido à ausência de profissionais no mercado. Isso porque há pouco investimento na área, também. O próprio profissional não se valoriza e não busca formação (NML, Intérprete formadora, 2018).

Infelizmente encontramos muitos intérpretes que se acomodam e não buscam formação. E outra dificuldade são cursos voltados para nossa área e quando encontramos são distantes da nossa cidade (KC, Intérprete formadora, 2018).

Penso que ainda não temos em nosso país um curso de nível superior que prepare o profissional para ser intérprete educacional em todos os níveis escolares, fica tudo a Deus dará! E ao intérprete a responsabilidade de se virar (APV, Intérprete formadora, 2018).

Nas respostas de NML e KC nota-se uma clara insatisfação quanto ao processo formativo e o apontamento das falhas desse processo nas falas: (a) ausência de profissionais no mercado, (b) há pouco investimento na área, (c) outra dificuldade são cursos voltados para área, (d) não se valoriza e não busca formação e (e) muitos intérpretes se acomodam. Nas falas "a", "b" e "c" são atribuídas falhas ao sistema político e educacional, ao passo, que nas falas "d" e "e" a atribuição de falhas é direcionada a própria atitude dos profissionais da área.

Na resposta de APV a falha é atribuída ao poder público e às instituições de ensino, evidente na fala ainda não temos em nosso país um curso de nível superior que prepare o profissional para ser intérprete educacional, entretanto há uma indicação inconsciente de solução para o problema ao dizer que cabe ao intérprete a responsabilidade de se virar, nessa fala ainda percebemos a presença clara de agência e autonomia do profissional, de não aceitar as condições e restrições impostas pelo sistema, direcionando portando suas escolhas (HUANG, 2013 e BENSON, 2017).

Ao ponderar sobre as respostas dos participantes, é possível responder às primeiras questões de pesquisa que sob a ótica dos ILSFs, a sua formação e a formação do TILSE no estado de Minas Gerais, ainda é insuficiente e desestruturada, apresentando falhas tanto por parte do poder público e educacional, quanto do próprio indivíduo, que ao ingressar no âmbito de trabalho adentra uma zona de conforto estagnando sua formação, isso é explicitado na fala de KC ao dizer que "infelizmente encontramos muitos intérpretes que se acomodam e não buscam formação".

Nesse viés, comprovando a existências de falhas no processo formativo, quando questionados sobre qual seria a melhor formação para eles e para os TILSEs, as respostas conferidas pelos participantes ao questionamento, embora tendo ocorrido em momentos distintos e individuais, parecem sugerir um consenso. As respostas compartilhadas abaixo, apontam uma clara evidência disso: 
suporte técnico-pedagógico para aprofundamento e melhoria na prática interpretativa de sala de aula (FFP, Intérprete formador, 2019).

Em minha opinião, as instituições de ensino superior e técnico, deveriam acatar o que dizem as leis e decretos e criar um curso de tradução e interpretação de Libras, e dentro desse curso criar disciplinas especificas para tradução educacional, disciplinas de didática e de psicologia da educação voltadas para questões de identidade e relações sociais (BLO, Intérprete formador, 2019).

Penso que o ideal para nós intérpretes formadores, era um curso de licenciatura com ênfase em tradução, com disciplinas que nos permitisse formar como professores e tradutores ao mesmo tempo [sic] (PPM, Intérprete formador, 2019).

Percebe-se, nos depoimentos de FFP, BLO e APV o desejo quanto a criação e instituição de um curso superior na modalidade de licenciatura com ênfase em tradução, ou técnico de tradução e interpretação como foco nos contextos educacionais, como possível solução para abordar as falhas anteriormente mencionadas, o que responde a terceira pergunta dessa pesquisa sobre qual seria a melhor formação para ILSFs e TILSEs em sua ótica. Assim, tais ideias refletidas pelos anseios dos colaboradores dessa pesquisa, podem ser as mesmas de outros profissionais do estado de Minas Gerais, incluindo a deste pesquisador. Portanto, as reflexões conclusivas desse trabalho serão apresentadas nas considerações a seguir.

\section{CONSIDERAÇÕES FINAIS}

Conforme apresentado, a formação do ILSF, no estado de Minas Gerais, é claramente um reflexo da agência e autonomia desse profissional, uma vez que nem o poder público, nem as instituições de ensino, até o presente momento, ofertam cursos que possam contribuir diretamente para sua prática. Nesse contexto, o profissional munido do desejo de executar suas funções e colaborar com as necessidades e defasagens de seus pares, empenha-se pela busca de conhecimentos técnicoespecíficos nas mais diversas áreas das ciências humanas, profissionalizando-se a partir de uma formação híbrida e mesclada que reflete suas metas e interesses pessoais.

Durante o desenvolvimento dessa pesquisa, foi possível perceber uma mudança de postura dos participantes, ao passo que ampliavam seu olhar quanto a sua formação e a de seus pares, para além da esfera estadual. Em tempo, induziu cada participante ao processo investigativo das políticas públicas vigentes, encetando ao grupo uma consciência crítica e reflexiva. Ao desenvolver uma consciência crítica, cada participante enveredou por um processo autoavaliativo que possibilitou identificar falhas de ordem pessoal em relação a sua formação continuada e à formação que conferem. Considerando esses processos, investigativo, autoavaliativo, crítico e reflexivo, embora a pesquisa foque em um nicho profissional específico, acredito que tais processos sejam vitais para o exercício da docência de qualquer professor, que ao conferir saberes e avaliar está exercendo o papel de formador.

Participar dessa pesquisa, ao longo dos dezoito meses em que foi desenvolvida, permitiu identificar as semelhanças existentes na construção da identidade profissional dos participantes, e compreender que cada formação, embora ocorra de forma única e autônoma, possui um objetivo em comum, o atendimento dos alunos surdos no espaço escolar. Analisar essas questões possibilitou também pensar estratégias que possam diminuir as falhas, ainda existentes, na formação profissional dos ILSFs e consequentemente dos TILSEs. 
Por fim, com as reflexões discutidas a partir das contribuições de cada participante, reunidas neste trabalho pelo pesquisador, apresenta-se a urgência em formular junto ao poder público e as instituições de ensino superior e/ou técnico, cursos que tenham por foco formar profissionais, munidos de saberes e competências para atuar no preparo de novos profissionais tornando-se multiplicadores e produtores de conhecimentos.

\section{REFERÊNCIAS}

ABRAHÃO, Maria Helena Vieira. A construção do conhecimento teórico-prático do professor de línguas em formação inicial. Contexturas, v. 23, p. 161-191, 2014.

ALBRES, N. A.; RODRIGUES, C. H. As funções do intérprete educacional: entre práticas sociais e políticas educacionais. Bakhtiniana. v. 13, p. 16-42, 2018.

ALMEIDA, Elomena Barboza De; LODI, Ana Claudia Balieiro. Formação de intérpretes de Libras Língua Portuguesa: Reflexões a partir de uma prática formativa. Libras em Estudo: Formação de Profissionais, São Paulo, p. 109-129, 2014.

ANDRÉ, Marli Eliza Dalmazo Afonso de. Etnografia da prática escolar. 15a ed. Papirus. Campinas. 2008. 128 p.

ASSIS SILVA, César Augusto. A constituição da língua brasileira de sinais: considerações sobre a missão protestante com surdos. Revista Sures, v. 3, p. 1-14, 2014.

ASSIS SILVA, César Augusto. O papel de agentes religiosos na surdez: considerações sobre a constituição da cultura surda. Espaço (Rio de Janeiro. 1990), v. 39, p. 5-16, 2013.

ASSIS SILVA, César Augusto. Cultura Surda: agentes religiosos e a construção de uma identidade. 1. ed. São Paulo: Terceiro Nome, 2012. v. 1. 248p.

BARCELOS, Ana Maria Ferreira. Unveiling the relationship between language learning beliefs, emotions, and identities. Studies in Second Language Learning and Teaching, Kalisz, v. 5, n. 2, p. 301-325, 2015.

BARCELOS, Ana Maria F. Identities as emotioning and believing. Reflections on Language Teacher Identity Research, p. 145, 2016.

BARKHUIZEN, Gary. Reflections on Language Teacher Identity Research.New York: Routledge. 2017.

BENSON, Phill. Teacher autonomy and teacher agency.p.18-23 In BARKHUIZEN, Gary. Reflections on Language Teacher Identity Research.New York: Routledge. 2017.

BRASIL. Casa Civil. Lei n.0 13.219, de $1^{\circ}$ de setembro de 2010. Regulamenta a profissão do tradutor e intérprete da Língua Brasileira de Sinais- LIBRAS.

BRASIL. Câmara dos Deputados. Projeto de Lei n.0 9.382 de 2017. Comissão de Defesa dos Direitos da Pessoa com Deficiência. Disponível em:

https://www.camara.leg.br/proposicoesWeb/prop_mostrarintegra;jsessionid=655BE338641A4DFAC CB14E3C87A42B29. proposicoesWebExterno2?codteor $=1639785$ \&filename $=$ Avulso+-PL+9382/2017. Acesso em 14/08/2019 às $11 \mathrm{~h} 10 \mathrm{~min}$. 
FERREIRA, Daiane. Estudo comparativo de currículos de cursos de formação de tradutores e intérpretes de libras-português no contexto brasileiro. Dissertação (mestrado) Universidade Federal de Santa Catarina, Centro de Comunicação e Expressão, Programa de PósGraduação em Estudos da Tradução, Florianópolis.2015. Disponível em: <https://repositorio.ufsc.br/xmlui/handle/123456789/169308>. Acesso em: 29 de maio de 2019.

FLICK, Uwe. Introdução à pesquisa qualitativa. 3 ed. Porto Alegre: Artmed, 2009. 405 p.

GIL, Antônio Carlos. Como Elaborar Projetos de Pesquisas. 6. ed. São Paulo: Atlas, 2016.

GUMIEIRO, A.H e PEREIRA, S.L.P. Intérprete da Língua Brasileira de Sinais: algumas considerações acerca do reconhecimento, formação e atuação. In. NUNES, E. O e CONSTÂNCIO, R.F.J. Libras: Reflexões e práticas educacionais. São Leopoldo. Oikos,179p.

HUANG, Jing. Autonomy, agencyandidentity in oreing language learning and teaching. Linguistic insights: studies in languageandcomunication. University of bergamo, v. 112, p. 54-77, jan. 2013.

LACERDA, C.B.F. de; BERNARDINO, B. M. O papel do intérprete de língua de sinais nas etapas iniciais de escolarização. In: LODI, A.C.B e LACERDA, C.B.F.: Uma escola duas línguas: letramento em língua portuguesa e língua de sinais nas etapas iniciais de escolarização. Porto Alegre: Editora Mediação, 2009.p.65-79.

LACERDA, C.B.F. de. Intérprete de Libras: em atuação na educação infantil e no ensino fundamental. Porto Alegre: Mediação/FAPESP, 2009.

MARTINS, Vanessa Regina De Oliveira; NASCIMENTO, Vinícius. Da formação comunitária à formação universitária (e vice-versa): novo perfil dos tradutores e intérpretes de línguas de sinais no contexto brasileiro. Cadernos de Tradução, Florianópolis, v. 35, n. 2, p. 78-112, jul./dez. 2015.

MARTINS, V. R. O.; NASCIMENTO, V. Da formação comunitária à formação universitária (e vice e versa): novo perfil dos tradutores e intérpretes de língua de sinais no contexto brasileiro.

Cadernos de Tradução, v. 35, p. 78, 2015.

MARTINS, Vanessa Regina de Oliveira. Tradutor e intérprete de língua de sinais educacional: desafios da formação. Belas Infiéis, v. 5, n. 1, p. 147-163, 2016.

MOURA, Izaulita César e CAVALCANTE, Fátima Gonçalves. O tradutor/intérprete de língua de sinais: um mediador de fronteiras culturais. Espaço. Rio de Janeiro, n.39. jan./jun. 2013

MINAS GERAIS. Secretaria de Estado de Educação. CAS: histórico e diretrizes de funcionamento. 2017. 62 p. Disponível em:

http://www2.educacao.mg.gov.br/images/documentos/CARTILHA_DIRETRIZES_CAS_OUTUBRO_1. pdf. Acesso em 14/08/2019 às 9h32min.

MINAS GERAIS. Resolução SEE 2903 de 2016. Disponível em: http://www2.educacao.mg.gov.br/images/documentos/2903-16-r.pdf. Acesso em 14/08/2019 às $10 \mathrm{~h} 58 \mathrm{~min}$.

MINAS GERAIS. Resolução SEE 3995 de 2018. http://www.designaeducacao.mg.gov.br/\#. Acesso em $14 / 08 / 2019$ às $10 \mathrm{~h} 58 \mathrm{~min}$.

NASCIMENTO, V.; BEZERRA, T. C. ; ALBRES, Neiva de Aquino ; SANTIAGO, Vania de Aquino Albres . Formação de Intérpretes Educacionais de Libras: entre concepções e propostas de curso de 
extensão universitária. In: V Congresso Brasileiro de Educação Especial, 2012, São Carlos. V CBEE - VII Encontro Nacional dos Pesquisadores da Educação Especial, 2012. p. 11745-11760.

NÓVOA, António. 2000. Vida de Professores. Porto: Porto Editora

QUADROS, R. M. de, \& STUMPF, M. R. (2009). O primeiro curso de graduação em letras língua brasileira de sinais: educação a distância. ETD - Educação Temática Digital, 10(2), 169185.

REICHMANN, Carla Lynn; ROMERO, Tania Regina de Souza. Language teachers' narratives and professional self-making. Delta. 2019, 35.3. p.1-25. Out/nov.2018.

SACKS, Oliver. Vendo vozes: Uma jornada pelo mundo dos surdos. Rio de Janeiro, RJ: Imago, 1989.

SACKS, Oliver. Vendo vozes: uma viagem ao mundo dos surdos.Tradução: Laura Teixeira Motta.São Paulo: Companhia das letras,2010. p.38.

SANTOS, Lara Ferreira Dos. 0 fazer do intérprete educacional: Práticas, estratégias e criações. 1. São Carlos: UFSCAR, 2014. 200 p.

SANTOS, Lara Ferreira dos; LACERDA, Cristina Broglia Feitosa de. Atuação do intérprete educacional: parceria com professores e autoria. Cadernos de Tradução (UFSC), v. 35, p. 505533, 2015.

SOUZA, Elizeu Clementino. Profissionalização, Fabricação de Identidade e Trabalho Docente: Alguns Apontamentos Teóricos. In Maria Cristina Faria Dalacorte Ferreira, Carla Lynn Reichmann; Tania Regina de Souza Romero (orgs.) Construções Identitárias de Professores de Línguas. Campinas: Pontes. 2016.

Submissão: 25/10/2021

Aceito: 08/12/2021

\footnotetext{
' Identidade do Docente de Línguas. O projeto visa a discutir e refletir sobre o processo de construção da identidade do docente de línguas materna e adicionais.

ii Consulta disponível em http://prp.ufla.br/comissoes/pesquisa-com-seres-humanos

iii Sacks (2010) utiliza o termo Surdez/Surdo (com S maiúsculo) para designar um grupo linguístico e cultural, em que o surdo é o indivíduo que aceita sua deficiência e se vê como diferente das pessoas ouvintes. Portanto usarei o termo "Surdo" com S maiúsculo para me referir às pessoas com deficiência auditiva usuárias da língua de sinais como primeira língua.

iv Tendo em vista a nomenclatura atribuída ao profissional pela Lei Federal 12.319/2010 será utilizado neste trabalho o termo: Tradutor e Intérprete de Libras.

$v$ MINAS GERAIS. Resolução SEE no. 2903 de 24 de fevereiro de 2016. Disponível em: http://www2.educacao.mg.gov.br/component/search/?all=resolu\%C3\%A7\%C3\%A30+2903\%2F2016\&area=all. Acesso em 14/08/2019 às 9h58min.

vi No original: Autonomy is not so much about controlling one's action of today or tomorrow (thought that may be part of it) but of directing current actions towards longer term-goals. (p.19)

vii Os nomes dos participantes foram substituídos por iniciais fictícias, a fim de conferir sigilo a sua identidade.
} 